\title{
Purification of El Tor cholera enterotoxins and comparisons with classical toxin
}

\author{
Rama S. Dubey, Marianne Lindblad and Jan Holmgren* \\ Department of Medical Microbiology and Immunology, University of Göteborg, Guldhedsgatan 10, S-413 46 \\ Göteborg, Sweden
}

(Received 21 November 1989; revised 10 April 1990; accepted 25 April 1990)

\begin{abstract}
In 55 clinical isolates of Vibrio cholerae biotype El Tor, cholera toxin (CT) production was higher after growth in liquid medium first under relatively anaerobic conditions followed by excessive aeration (AKI conditions) as compared with growth under the optimal conditions for CT production from $V$. cholerae of classical biotype (median toxin level being $400 \mathrm{ng} \mathrm{ml}^{-1}$ and $1 \mathrm{ng} \mathrm{ml}^{-1}$ respectively, for the two different growth conditions). Large growth volumes further enhanced El Tor toxin production to levels at or above $3-5 \mu \mathrm{g} \mathrm{ml}^{-1}$ from several strains, which allowed for easy purification of toxin by salt precipitation, aluminium hydroxide adsorption and/or $\mathbf{G M}_{1}$ ganglioside affinity chromatography. However, such purified EI Tor CT completely lacked the A subunit when examined by SDS-PAGE or by monoclonal anti-A subunit antibody GM $_{1}$-ELISA. In contrast, when El Tor CT was prepared from bacteria grown in the presence of specific antiserum against soluble haemagglutinin/protease it contained the A subunit (unnicked) in the same proportion to the B subunit (1A:5B) as classical CT. Immunodiffusion-in-gel tests revealed that the B subunits of El Tor and classical CTs share major epitopes but also have one or more weaker biotype-specific epitopes. The two types of toxin were practically indistinguishable in

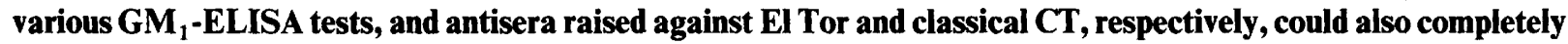
neutralize the heterologous as well as the homologous toxin activity in vivo. The results indicate that CTs from EI Tor and classical $V$. cholerae, despite demonstrable epitope differences, are predominantly cross-reactive and give rise to antisera with strong cross-neutralizing activity.
\end{abstract}

\section{Introduction}

Vibrio cholerae of serogroup $\mathrm{O} 1$ produces a potent heatlabile enterotoxin, termed cholera toxin (CT). In individuals infected with $V$. cholerae, $\mathrm{CT}$ is responsible for the drastic intestinal electrolyte secretion and fluid loss leading to the clinical state of cholera (Finkelstein \& Lospalluto, 1969; Holmgren, 1981; Finkelstein, 1984). $\mathrm{CT}$ is a multimeric protein with two types of subunits (Lönnroth \& Holmgren, 1973; Holmgren, 1981). Five B subunits (CTB) mediate binding to $\mathrm{GM}_{1}$-ganglioside receptors on the target cell surface. A single A subunit (CTA) catalyses NAD-dependent ADP-ribosylation of the adenylate cyclase regulatory protein $\mathrm{Gs}(\mathrm{Ns})$, thereby activating adenylate cyclase to stimulate cAMP production (Holmgren et al., 1974; Moss \& Vaughan, 1977).

Abbreviations: $\mathrm{CT}$, cholera toxin; CTA/CTB, cholera toxin subunit A/B; HA, haemagglutinin; mAb, monoclonal antibody.
Although $V$. cholerae $\mathrm{O} 1$ strains of the classical biotype have long been recognized as causative agents of cholera and many such strains are relatively potent toxin producers in vitro, the vast majority of cholera cases during recent years have been caused by strains of the El Tor biotype (Black, 1986), whose CT-producing ability is much less well defined. Among classical $V$. cholerae strains, CT produced by the hyperproducing strain 569B is regarded as the prototype and various culture media have been developed in order to increase in vitro $\mathrm{CT}$ production by this strain and to characterize the toxin (Finkelstein et al., 1966; Kusama \& Craig, 1970; Mekalanos et al., 1978; Tayot et al., 1981). Most $V$. cholerae of the El Tor biotype, on the other hand, produce quite low or undetectable levels of CT using the culture conditions found to support high levels of CT production by classical strains (Iwanaga \& Kuyyakanond, 1987). Only recently with the description of a new procedure, the so-called AKI method (Iwanaga 
\& Yamamoto, 1985), which specifically increases in vitro CT production from El Tor strains of $V$. cholerae to levels similar to those produced by classical strains, has it become possible to undertake a biochemical and immunological characterization of El Tor CT in comparison with classical (569B) CT. In particular, since the CTBs from 569B CT have been used in a recently developed oral cholera vaccine for inducing antitoxic cholera immunization (Svennerholm \& Holmgren, 1986), it is important to determine the degree of immunological relationship between classical (569B) and El Tor CTB.

\section{Methods}

Bacterial strains. We used 55 strains of $V$. cholerae $\mathrm{E} 1$ Tor isolated from cholera patients from different places since 1965; the majority of the strains were isolated in Bangladesh in 1983-85 and were obtained through the courtesy of the International Centre for Diarrhoeal Disease Research, Bangladesh (ICDDR.B).

Media and culture conditions. CT production was tested by growing all strains in Syncase and AKI media under different conditions. In Syncase medium (Finkelstein et al., 1966) one colony from a 24-h-old blood agar plate (approx. $10^{7}$ organisms) was inoculated in $10 \mathrm{ml}$ of medium in $250 \mathrm{ml}$ Erlenmeyer flasks and cultured at $37^{\circ} \mathrm{C}$ for $24 \mathrm{~h}$ with continuous shaking at 200 cycles min $^{-1}$. For CT production in AKI medium (Iwanaga et al., 1986) the organisms were initially cultured statically at $37^{\circ} \mathrm{C}$ for $4 \mathrm{~h}$ in $10 \mathrm{ml}$ cylinders $(1 \mathrm{~cm}$ diameter) containing $10 \mathrm{ml}$ medium. The $10 \mathrm{ml}$ cultures were then transferred into $250 \mathrm{ml}$ Erlenmeyer flasks, and incubation continued under rapid agitation $\left(200\right.$ cycles $\left.\mathrm{min}^{-1}\right)$ for $16 \mathrm{~h}$ at $37^{\circ} \mathrm{C}$. The AKI medium $[1.5 \%(\mathrm{w} / \mathrm{v})$ Bacto-Peptone, $0.4 \%$ yeast extract (Difco), $0.5 \% \mathrm{NaCl}$ and $0.3 \%$ $\mathrm{NaHCO}_{3}$ ] was prepared as described by Iwanaga et al. (1986). The sodium bicarbonate was filter-sterilized separately and mixed with the other autoclaved ingredients. Freshly prepared medium was always used; the $\mathrm{pH}$ of this medium was near 7.4 without adjustment.

Strains VM10289, VM12260, VM14169 and VM12718 were further examined for optimum CT production in AKI medium using different volumes of stationary and shaking cultures. These four strains were initially cultured statically for $4 \mathrm{~h}$ in 10,100 and $500 \mathrm{ml}$ volumes of medium in cylinders and the cultures were then transferred into 250 , 1000 and $2000 \mathrm{ml}$ flasks, respectively, for $16 \mathrm{~h}$ of further incubation with shaking.

Salt precipitations. For the purpose of purifying CTB from E1 Tor strains VM10289 and VM14169, three sets of $500 \mathrm{ml}$ cultures obtained after stationary incubation for $4-5 \mathrm{~h}$ followed by shake-incubation for 16-18 h were centrifuged at $10000 \mathrm{~g}$ for $40 \mathrm{~min}$.

(a) Ammonium sulphate precipitation ( $90 \%$ saturation) was done by slowly adding solid ammonium sulphate $\left(662 \mathrm{~g} \mathrm{1}^{-1}\right)$ to $500 \mathrm{ml}$ icechilled culture supernatant with continuous stirring and maintaining the $\mathrm{pH}$ at 7.2 with $3 \mathrm{M}-\mathrm{NaOH} / \mathrm{HCl}$. The mixture was left overnight at $4{ }^{\circ} \mathrm{C}$ and the precipitate pelleted by centrifugation $(16000 \mathrm{~g}, 20 \mathrm{~min})$ at $4{ }^{\circ} \mathrm{C}$ and dissolved in $5 \mathrm{ml}$ phosphate-buffered saline (PBS; $0.15 \mathrm{M}$-sodium chloride; $0 \cdot 1 \mathrm{M}$-sodium phosphate, $\mathrm{pH}$ 7.2).

(b) Precipitation with sodium hexametaphosphate was done by adjusting the $\mathrm{pH}$ of the culture supernatant to 4.5 with $6 \mathrm{M}-\mathrm{HCl}$, followed by addition of the salt to a final concentration of $1 \mathrm{~g} \mathrm{l}^{-1}$. The mixture was stirred for $2 \mathrm{~h}$ in the cold and the precipitate was then collected by centrifugation $(10000 \mathrm{~g}, 15 \mathrm{~min})$ at $4{ }^{\circ} \mathrm{C}$ and dissolved in $5 \mathrm{ml}$ PBS, pH 7.2. (c) Aluminium hydroxide powder $\left(1 \mathrm{mg} \mathrm{m}^{-1}\right)$ was added to $500 \mathrm{ml}$ volumes of culture supernatants after adjustment of $\mathrm{pH}$ to $5 \cdot 0$ with $6 \mathrm{M}-\mathrm{HCl}$. Contents were stirred for $6 \mathrm{~h}$ in the cold. The aluminium hydroxide precipitate was then collected by centrifugation $(12000 \mathrm{~g}$, $15 \mathrm{~min}$ ) at $4{ }^{\circ} \mathrm{C}$ and washed three times with $0.01 \mathrm{M}$-ammonium formate. Toxin adsorbed on aluminium hydroxide was eluted with $5 \mathrm{ml}$ TEAN buffer $\left(50 \mathrm{~mm}\right.$-Tris/HCl, $1 \mathrm{~mm}$-EDTA, $3 \mathrm{mM}-\mathrm{NaN}_{3}$ and $0 \cdot 2 \mathrm{M}-\mathrm{NaCl} ; \mathrm{pH} 8 \cdot 5)$.

Purification of El Tor CTB. Strain VM10289, isolated from a cholera patient in Bangladesh during 1983, was used. It was streaked on 10 blood agar plates and, after incubation at $37^{\circ} \mathrm{C}$ for $24 \mathrm{~h}, 50$ colonies from surface growth were transferred to each of 10 measuring cylinders containing $500 \mathrm{ml}$ culture medium. After stationary growth at $37^{\circ} \mathrm{C}$ for 4-5 $\mathrm{h}$ the contents were transferred to 21 Erlenmeyer flasks and were shaken for $16-18 \mathrm{~h}$ at a constant speed of 200 oscillations $\mathrm{min}^{-1}$. Cells were harvested by centrifugation at $10000 \mathrm{~g}$ for $40 \mathrm{~min}$ at $4{ }^{\circ} \mathrm{C}$. Supernatants were pooled and after adjustment of $\mathrm{pH}$ to 4.5 with $6 \mathrm{M}-\mathrm{HCl}$ precipitation was done with sodium hexametaphosphate $\left(1 \mathrm{~g} \mathrm{l}^{-1}\right)$ as described above. The precipitate was dissolved in $10 \mathrm{ml}$ $\mathrm{PBS}, \mathrm{pH} 7 \cdot 2$, and then passed through a Millipore bacterial filter $(0.22 \mu \mathrm{m}$ pore size $)$.

Affinity chromatography on lyso- $\mathrm{GM}_{1}$ ganglioside-Spherosil (Tayot et al., 1981) was done at $4{ }^{\circ} \mathrm{C}$ with $10 \mathrm{ml}$ sterile sodium hexametaphosphate-precipitated toxin. A lyso- $\mathrm{GM}_{1}$ ganglioside-Spherosil column $(1.2 \times 1.0 \mathrm{~cm})$ was packed in $10 \mathrm{~mm}-\mathrm{PBS}$, pH 6.8 , containing $10 \mathrm{~g} \mathrm{NaCl}^{-1}$, and the column was washed thoroughly with this PBS. A toxin preparation containing $7.2 \mathrm{mg}$ protein was loaded on the column and $1 \mathrm{ml}$ eluates were collected with continuous elution ('washing') with the same buffer (PBS, pH 6.8) until the $A_{280}$ of the eluate was near zero, as monitored using a Shimadzu UV-Vis spectrophotometer. Further 'specific' elution was made with $50 \mathrm{~mm}$-sodium citrate buffer, $\mathrm{pH} 2.8$, and $1 \mathrm{ml}$ elution volumes were collected. $A_{280}$ values of the fractions were recorded and the four or five fractions showing significant absorbance were pooled, neutralized with $0.1 \mathrm{M}-\mathrm{NaOH}$ and then concentrated by ultrafiltration from approximately 5 to $1 \mathrm{ml}$ volume using a YM2 Amicon Ultrafilter membrane $\left(M_{\mathrm{r}}\right.$ cutoff $>1000$ ).

SDS-PAGE. This was done as described by Laemmli (1970) using $12 \%$ or $13.5 \%(\mathrm{w} / \mathrm{v})$ polyacrylamide as separating gel and a $4 \%$ stacking gel. $M_{\mathrm{r}}$ marker proteins (Bio-Rad) were lysozyme (14400), soybean trypsin inhibitor $(21500)$, carbonic anhydrase $(31000)$, ovalbumin (45000), BSA (66200) and phosphorylase $b$ (92500). After the run, protein bands were visualized by staining with Coomassie brilliant blue.

CT production in the presence of anti-haemagglutinin antibody and determination of subunit structure. Soluble haemagglutinin (HA) was purified from a classical $V$. cholerae strain $0717 \mathrm{R}$ and an antiserum was raised in adult New Zealand White rabbits as described by Svennerholm et al. (1983). The classical strain 569B and El Tor strain VM45216 were each grown in duplicate $10 \mathrm{ml}$ aliquots of AKI medium. Then $0.1 \mathrm{ml}$ of specific antiserum (see above) was added to one of the aliquots and $0.1 \mathrm{ml}$ of pre-immune serum from the same rabbit to the other aliquot as control, the cultures were transferred to $250 \mathrm{ml}$ Erlenmeyer flasks, and incubation was continued for $16 \mathrm{~h}$ with vigorous shaking for production of toxin. Bacterial cells were then removed by centrifugation at $22000 \mathrm{~g}$ for $10 \mathrm{~min}$ at $4{ }^{\circ} \mathrm{C}$, and $\mathrm{GM}_{1}$ ganglioside-derivatized cellulose particles (Tayot et al., 1981) were added to the supernatants to bind the secreted cholera enterotoxin: $50 \mathrm{mg}$ of $\mathrm{GM}_{1}$-cellulose containing about $35 \mu \mathrm{g} \mathrm{GM}_{1}\left[0.5 \mu \mathrm{mol} \mathrm{GM}_{1}\right.$ ( $\mathrm{g}$ cellulose $)^{-1}$ ] was added to $4 \mathrm{ml}$ culture supernatant and the mixture gently stirred for $1 \mathrm{~h}$ at $4^{\circ} \mathrm{C}$. Contents were then centrifuged and the pellets washed three times with PBS (pH 7.2). The pellets were then suspended in $30 \mu \mathrm{I}$ SDS-PAGE sample buffer containing $2 \%$ (w/v) SDS 
and $5 \%(w / v) \beta$-mercaptoethanol and boiled for $5 \mathrm{~min}$ at $100{ }^{\circ} \mathrm{C}$. Aliquots $(10 \mu \mathrm{l})$ of boiled preparations were used for SDS-PAGE analyses (see above).

Preparation of rabbit antisera against CT preparations. Antisera were produced in adult New Zealand White rabbits given three to four subcutaneous injections, 2 weeks apart, with purified CT preparations ( $30 \mu \mathrm{g}$ per injection) from either classical $V$. cholerae strain $569 \mathrm{~B}$ or $\mathrm{El}$ Tor VM45216; the initial two injections were given with Freund's complete adjuvant. Animals were bled 2 weeks after the last injection and the sera were stored at $-30^{\circ} \mathrm{C}$. Monoclonal antibodies (mAbs) reacting with CTA ( $\mathrm{mAb}$ CT17) or CTB (mAb LT39) were prepared and evaluated by ELISA and GM $_{1}$-ELISA methods as described previously (Lindholm et al., 1983; Svennerholm et al., 1986).

Assay of CT. Levels of CT at various stages of preparations were detected by $\mathrm{GM}_{1}$-ELISA done as a microtitre modification of the original procedure described by Holmgren (1973). Different dilutions of test toxin preparation were incubated in polystyrene microtitre trays which had been pre-coated with $\mathrm{GM}_{1}$ ganglioside. The specifically bound toxin antigen was then quantified by means of mAb (or polyclonal antiserum) and appropriate immunoenzyme reagents. Reactivity of CT preparations from $V$. cholerae El Tor strain VM10289 and classical strain 569B was determined in a GM $_{1}$-ELISA system using mAbs specific to CTA (mAb CT17) and CTB (mAb LT39); these $\mathrm{mAbs}$ have been found to react with highly conserved enterotoxin epitopes found in both cholera toxin and Escherichia coli LT from many strains tested (unpublished data). The relative reactivities of CTs from El Tor and classical biotypes with homologous and heterologous antisera were examined using either different concentrations of CTs and excess of antisera, or saturating concentrations of CT and serial dilutions of homologous and heterologous antisera.

Immunodiffusion. Immunodiffusion analyses in gels were done according to the method of Ouchterlony \& Nilsson (1978) using the microplate modification devised by Wadsworth (1957).

Neutralization test. The capacity of the antisera raised against El Tor and classical toxins to neutralize the homologous and the heterologous toxin was evaluted by the rabbit skin test (Craig, 1965). Organisms were grown in AKI medium in the presence of antiserum to soluble HA in $10 \mathrm{ml}$ volumes with $4 \mathrm{~h}$ stationary phase followed by $16 \mathrm{~h}$ shake culture. Culture supernatants from 10 strains, whose toxin production had been measured by $\mathrm{GM}_{1}$-ELISA in a pre-test $1-2 \mathrm{~d}$ earlier, were adjusted to contain approximately $0.15 \mu \mathrm{g}$ toxin $\mathrm{ml}^{-1}$ (based on the pretest toxin levels) and mixed in equal volumes with $1: 10$ dilutions of different antisera in PBS $/ 0.1 \%$ BSA. After incubation at $23{ }^{\circ} \mathrm{C}$ for $60 \mathrm{~min}, 0.1 \mathrm{ml}$ of the mixture was injected intracutaneously into rabbits and assayed for permeability factor activity; each sample was tested in each of two or three rabbits at two different positions. When antiserum mixed with the toxin resulted in a diminished zone of blueing and induration compared with the normal rabbit serum mixed with the toxin, the antiserum was judged to have neutralizing activity (Lindholm et al., 1983).

\section{Results}

\section{CT production by El Tor vibrios}

Fifty-five strains of El Tor vibrios were examined for CT production in Syncase medium $\left(37^{\circ} \mathrm{C}, 24 \mathrm{~h}\right.$ in shaken flasks in $10 \mathrm{ml}$ volumes). It was observed that 26 strains $(47 \%)$ produced less than $1 \mathrm{ng}$ toxin $\mathrm{ml}^{-1}$ and the remaining 29 strains $(53 \%)$ between 1 and $40 \mathrm{ng} \mathrm{ml}^{-1}$
(Fig. 1). When these strains were instead cultured in AKI medium with a $4 \mathrm{~h}$ stationary culture followed by $16 \mathrm{~h}$ shaking cultures $\left(37^{\circ} \mathrm{C}, 10 \mathrm{ml}\right.$ volumes) only seven strains $(13 \%)$ produced less than $2 \mathrm{ng} \mathrm{CT} \mathrm{ml}^{-1}$ whereas in the other strains $(87 \%)$ toxin production ranged between 54 and $1736 \mathrm{ng} \mathrm{ml}^{-1}$. Nine out of 55 strains produced more than $1 \mu \mathrm{g}$ toxin $\mathrm{ml}^{-1}$ under these AKI conditions.

With the four El Tor strains examined in greater detail (VM10289, VM12260, VM14169 and VM12718) the AKI culture volume affected toxin production (Table 1). Using similar inoculum size and culture conditions all strains produced more toxin when cultured in $500 \mathrm{ml}$ volumes than at $100 \mathrm{ml}$ or $10 \mathrm{ml}$. Among the four El Tor strains tested, VM10289 and VM14169 produced the highest levels, 5.9 and $5.3 \mu \mathrm{g}$ toxin $\mathrm{ml}^{-1}$, respectively, in $500 \mathrm{ml}$ culture volumes, and these strains were selected for further toxin purification studies. In all our experiments we always used freshly prepared AKI medium, as CT production in this medium drastically decreased when the medium was stored even at $10^{\circ} \mathrm{C}$ for $5-7 \mathrm{~d}$.

\section{Purification and preliminary characterization of $C T$}

To achieve a convenient salt-precipitation step to purify CT from strains VM10289 and VM14169, the usefulness of ammonium sulphate, sodium hexametaphosphate or aluminium hydroxide was tested in $500 \mathrm{ml}$ culture supernates. The maximum recovery of CT $(41.5 \%)$ was obtained using sodium hexametaphosphate $\left(1 \mathrm{mg} \mathrm{ml}^{-1}\right)$ and strain VM10289; however, this salt functioned less well with strain VM14169, only about $4-5 \%$ of CT being recovered. Recovery of toxin after adsorption to aluminium hydroxide $\left(1 \mathrm{mg} \mathrm{ml}^{-1}\right)$ was $18-22 \%$, similar for both strains tested. Recovery of ammonium sulphate $(90 \%$ saturation level) precipitated toxin was $11-16 \%$ from the supernates of both strains. In general, the recovery of $\mathrm{El}$ Tor $\mathrm{CT}$ after precipitation by inorganic salts was substantially less than that of classical $V$. cholerae $569 \mathrm{~B}$ toxin.

Each of the salt-precipitated El Tor CT preparations could be further purified by affinity chromatography on lyso-GM $M_{1}$ ganglioside-Spherosil using the same conditions and with a similar efficacy as experienced with classical CT (not shown).

We examined the electrophoretic patterns of concentrated culture supernate, salt-precipitated and affinitypurified CTs from strain VM10289. Whilst sodium hexametaphosphate precipitation provided a higher yield of CT compared to the other salts tested, the precipitate obtained also contained many other proteins from the culture supernate. In contrast, purification of protein by adsorption to aluminium hydroxide resulted in an almost pure CT showing a single band in 


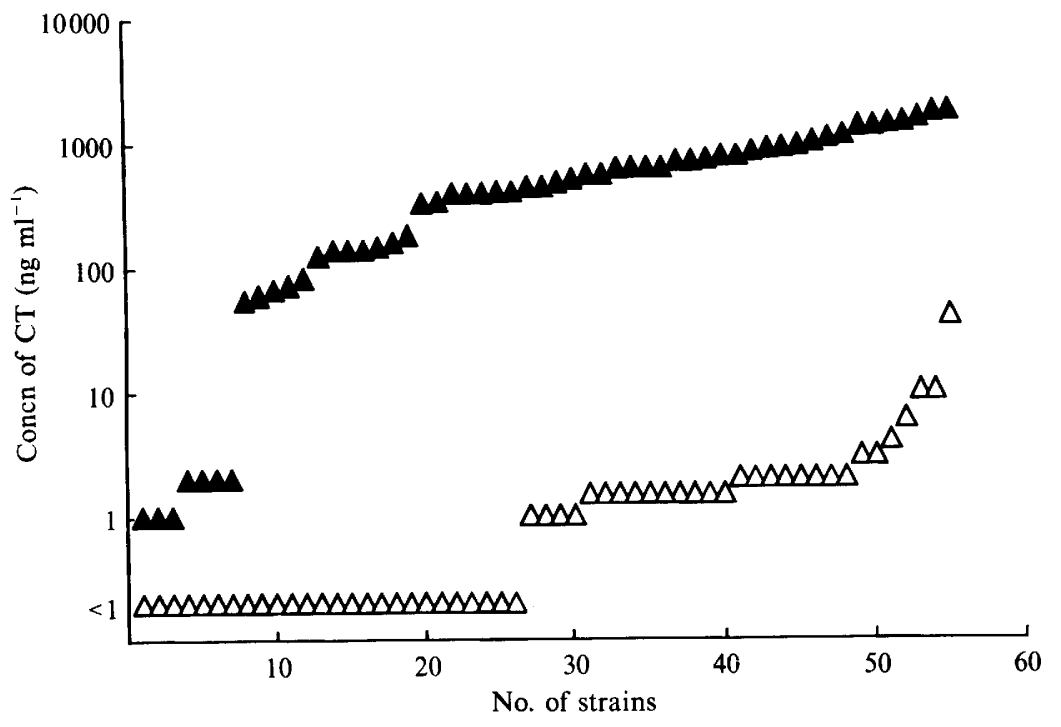

Fig. 1. Production of CT by $55 \mathrm{~V}$. cholerae El Tor strains in Syncase $(\Delta)$ and AKI $(\Delta)$ media. Organisms were grown in Syncase medium at $37^{\circ} \mathrm{C}$ for $24 \mathrm{~h}: 10 \mathrm{ml}$ volumes were incubated in $250 \mathrm{ml}$ Erlenmeyer flasks maintained with shaking at 200 cycles $\mathrm{min}^{-1}$. In AKI medium, organisms were initially cultured statically in $10 \mathrm{ml}$ volumes in $10 \mathrm{ml}$ measuring cylinders for $4 \mathrm{~h}$ at $37^{\circ} \mathrm{C}$ and then the culture was transferred into $250 \mathrm{ml}$ Erlenmeyer flasks and incubation continued with shaking for $16 \mathrm{~h}$ at $37^{\circ} \mathrm{C}$.

Table 2. Reactivity of $V$. cholerae El Tor CT preparations from strain VM10289 against anti-A and anti-B $M A b s$ in $a$

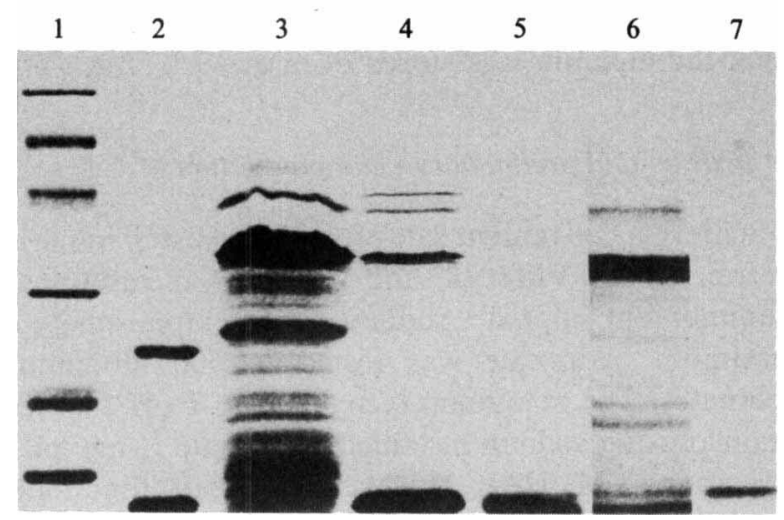
$G M_{1}-E L I S A$ system

$A_{450}$ values represent the means of triplicate observations.

\begin{tabular}{llc}
\hline \hline & \multicolumn{2}{c}{$A_{450}$} \\
\cline { 2 - 3 } Preparation & Anti-A (CT17) & Anti-B (LT39) \\
\hline $\begin{array}{l}\text { VM10289 CT } \\
\text { Fresh culture supernate }\end{array}$ & 0.659 & 1.304 \\
$\begin{array}{l}\text { Sodium hexametaphosphate- } \\
\text { precipitated toxin }\end{array}$ & 0.013 & 1.497 \\
Ammonium sulphate- & 0.015 & 1.682 \\
precipitated toxin & & \\
Aluminium hydroxide- & 0.005 & 1.494 \\
adsorbed toxin & 0.000 & 1.839 \\
Affinity purified toxin & 0.838 & 1.252 \\
569B CT & & \\
\hline \hline
\end{tabular}

Fig. 2. SDS-PAGE of El Tor CT from strain VM10289 at differen stages of purification. All samples were reduced and heated at $100{ }^{\circ} \mathrm{C}$ for $5 \mathrm{~min}$ before being electrophoresed on $12 \%(\mathrm{w} / \mathrm{v})$ polyacrylamide separating gel containing SDS. Lanes: $1, M_{\mathrm{r}}$ markers as specified in Methods; 2, purified standard CT (569B classical toxin); 3, culture supernatant concentrated 10-fold by Amicon Membrane YM-10 ultrafiltration; 4, sodium hexametaphosphate $\left(1 \mathrm{mg} \mathrm{ml}^{-1}\right)$ precipitated toxin; 5, lyso- $\mathrm{GM}_{1}$-ganglioside-Spherosil affinity-purified toxin; 6 , ammonium sulphate ( $90 \%$ saturation)-precipitated toxin; 7 , aluminium hydroxide $\left(1 \mathrm{mg} \mathrm{ml}^{-1}\right)$-adsorbed toxin.

Table 1. Variation in CT production by $V$. cholerae El Tor strains in different volumes of culture in AKI medium

\begin{tabular}{lccc}
\hline & \multicolumn{3}{c}{ Concn of CT $\left(\mu \mathrm{g} \mathrm{ml}^{-1}\right)$} \\
\cline { 2 - 4 } Strain no. & $10 \mathrm{ml}$ & $100 \mathrm{ml}$ & $500 \mathrm{ml}$ \\
\hline VM10289 & 0.65 & 3.21 & 5.9 \\
VM12260 & 0.06 & 1.77 & 3.06 \\
VM14169 & 0.12 & 1.39 & 5.27 \\
VM12718 & 0.10 & 0.44 & 0.88 \\
\hline \hline
\end{tabular}

SDS-PAGE at the expected position for CTB. Sodiumhexametaphosphate-precipitated CT, when further subjected to affinity chromatography on a lyso- $\mathrm{GM}_{1}$ ganglioside-Spherosil column and eluted with $\mathrm{pH} 2 \cdot 8$ citrate buffer, likewise yielded a pure protein with a migration rate corresponding to CTB (Fig. 2).

No protein-staining band was observed at the position for CTA (or its $A_{1}$ fragment) in the SDS-PAGE analyses of El Tor CT purified with either aluminium hydroxide alone or the combination of sodium hexametaphosphate precipitation and $\mathrm{GM}_{1}$ affinity chromatography (Fig. 2). When toxin preparations at different stages of purification were examined in $\mathrm{GM}_{1}$-ELISA systems for their reactivity against mAbs to CTA (anti-A, CT17) and CTB (anti-B, LT39), both the aluminium-hydroxideadsorbed $\mathrm{CT}$ and the affinity-purified $\mathrm{CT}$ lacked reactivity with anti-A (Table 2 ). CT precipitated with 
sodium hexametaphosphate or ammonium sulphate also did not show significant reaction with anti-A. Under similar conditions purified CT from the classical 569B strain reacted strongly with anti-A (Table 2 ).

\section{Subunit structure of El Tor CT}

The observation that CT purified from El Tor $V$. cholerae strains practically lacked CTA when examined with SDS-PAGE and GM $_{1}$-ELISA (see above) could imply either that CTA was not produced under the growth conditions used for the El Tor strains, or that it was selectively degraded. In previous studies we have demonstrated production of higher levels of soluble HA/protease from El Tor as compared with classical $V$. cholerae strains (Svennerholm et al., 1983; G. Jonson and others, unpublished) and we have found that besides specifically nicking CTA between its $A_{1}$ and $A_{2}$ fragments this protease may also, at higher protease concentration and/or longer exposure, more extensively degrade CTA.

We therefore tested the possibility that the apparent lack of CTA in CT from El Tor cholera vibrios was due to selective degradation of this subunit by soluble HA/protease being concomitantly produced by the vibrios. Two $V$. cholerae strains, 569B and VM45216, of classical and El Tor biotype, respectively, were each grown in $10 \mathrm{ml}$ containers under AKI conditions in the presence or absence of specific antiserum against soluble HA. CT in culture medium was affinity-bound to $\mathrm{GM}_{1}$ ganglioside-derivatized cellulose particles and, after washing, was eluted with boiling SDS and examined by SDS-PAGE. The results, shown in Fig. 3, reveal that CT from El Tor vibrios, when produced in the presence of specific antiserum neutralizing soluble HA, contained the same proportion of CTA to CTB as classical cholera toxin; in both toxins the CTA was unnicked, supporting a specific role for soluble HA in the nicking of either toxin (Fig. 3, lanes 3 and 5). In the absence of insoluble $\mathrm{HA}$, bacteria of strain 569B apparently produced enough soluble HA to nick CTA without degrading it (Fig. 3, lane 2), whilst VM45216 (E1 Tor) produced so much of this strong protease that it caused degradation of most of the CTA (Fig. 3, lane 4).

\section{Immunological properties of El Tor toxin}

Since purified CTB from classical $V$. cholerae (strain 569B) is an important component in a newly developed oral vaccine (Svennerholm \& Holmgren, 1986), it was deemed important to determine the immunological relationship between classical and El Tor CTs, especially with regard to CTBs. We therefore prepared rabbit

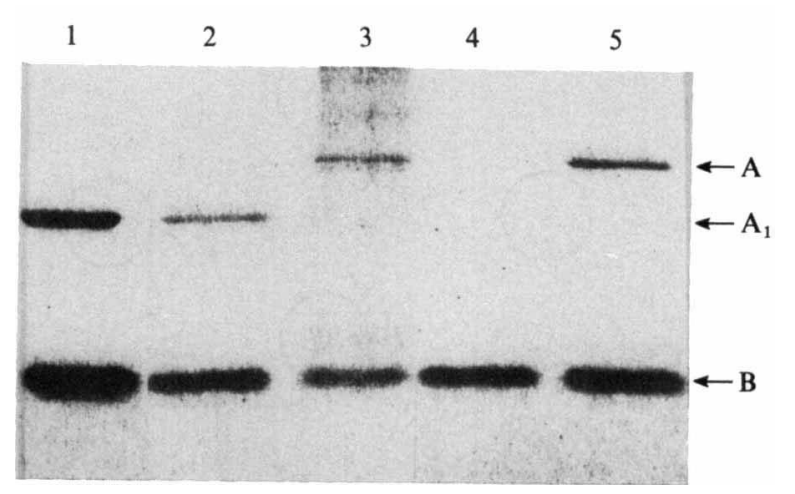

Fig. 3. SDS-PAGE of toxin preparations from strains 569B and VM45216 grown in the absence and presence of antibodies against soluble HA. The compositions of the gels and buffers were according to Laemmli (1970) with a $13.5 \%(\mathrm{w} / \mathrm{v})$ polyacrylamide separating gel and a $4 \%(w / v)$ polyacrylamide stacking gel. The samples were boiled for $5 \mathrm{~min}$ in the sample buffer containing $2 \%(\mathrm{w} / \mathrm{v})$ SDS and $5 \%$ $\beta$-mercaptoethanol before electrophoresis. Lanes: 1 , purified standard (classical) CT with typically nicked CTA; 2 , toxin from 569B grown in presence of control rabbit serum (in final concentration 1:100 dilution and prepared from a pre-immunization bleeding of the same rabbit which provided the specific anti-HA antiserum); 3, toxin from 569B grown in the presence of the same concentration of rabbit antiserum to HA; 4, toxin from El Tor VM45216 after growth with control rabbit serum; 5, toxin from VM45216 after growth in the presence of HA antiserum.

antisera against CTs purified from either classical (569B) or El Tor (VM45216) for immunological comparisons between toxins and CTB preparations from classical and El Tor $V$. cholerae, respectively.

Ouchterlony tests. Immunodiffusion-in-gel analyses by the method of Ouchterlony \& Nilsson (1978) demonstrated that both the El Tor and classical CTBs had major shared epitopes as well as seemingly weaker biotype-specific ones. The latter epitopes resulted in faint 'spurs' extending from the heavy coalescent immunoprecipitation bands formed by the strong common epitopes (Fig. 4).

$G M_{1}-E L I S A$. It was important to determine the relative importance of the shared and specific epitopes for the interactions of El Tor and classical CTs with homologous and heterologous antitoxin antisera, respectively, as well as for binding to receptor $\mathrm{GM}_{1}$ ganglioside. With this in mind we examined by $\mathrm{GM}_{1}$-ELISA the relative activity of the two types of toxin, on a weight basis, to bind to plastic-coated $\mathrm{GM}_{1}$ ganglioside and then to react with homologous or heterologous antitoxin antiserum. The results, presented in Fig. 5(a), show that the two types of CT were indistinguishable in both $\mathrm{GM}_{1}$ ganglioside and antiserum reactivity. Since in these 

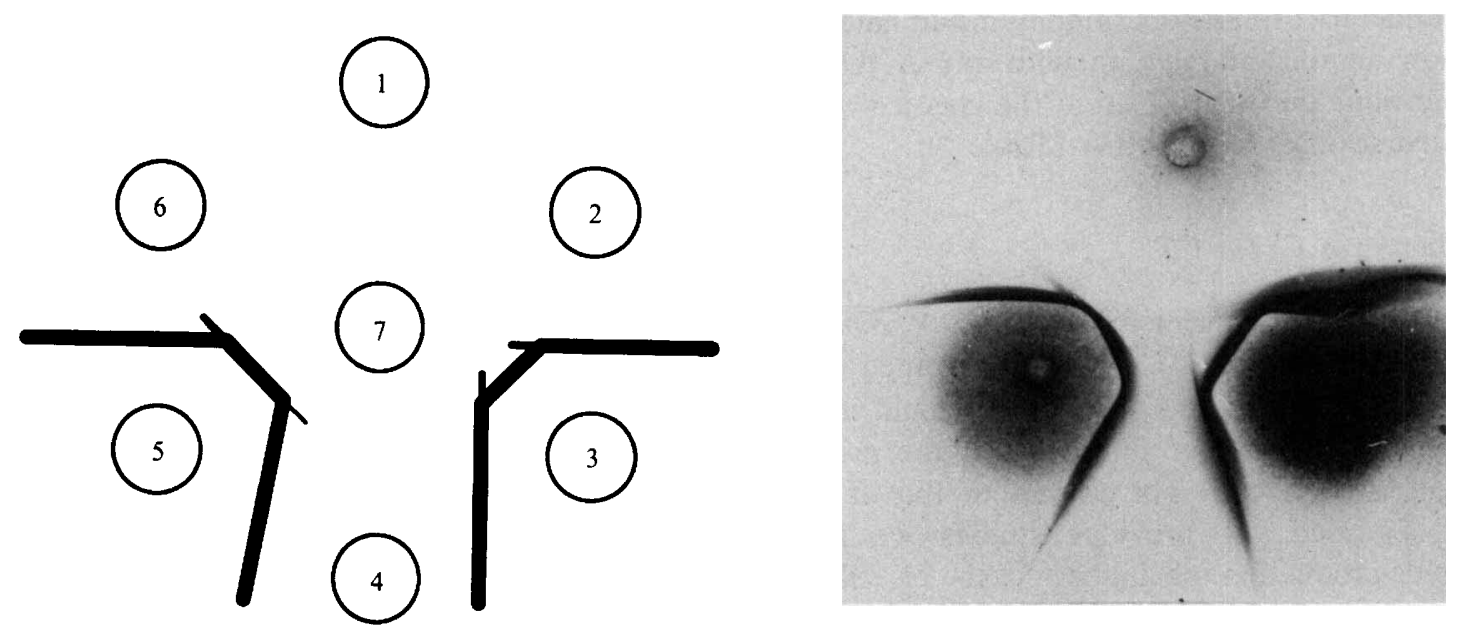

Fig. 4. Ouchterlony immunodiffusion test of CTB preparation from one El Tor and two classical $V$. cholerae strains as tested with homologous and heterologous antitoxin immune sera. Diffusion system: 1, rabbit antiserum to CTA (classical) from 569B CT; 2, purified CTB from 569B; 3, rabbit antiserum to 569B CTB; 4, purified recombinant classical CTB derived from strain VM10289; 5, rabbit antiserum to El Tor CTB; 6, same as well 2; 7, purified E1 Tor CTB. Note the strong coalescing immunoprecipitation bands representing the shared major epitopes between classical and El Tor CTB preparations, and the additional much fainter 'spur'-like extensions from both classical and El Tor CTBs indicating presence of minor biotype-specific epitopes.
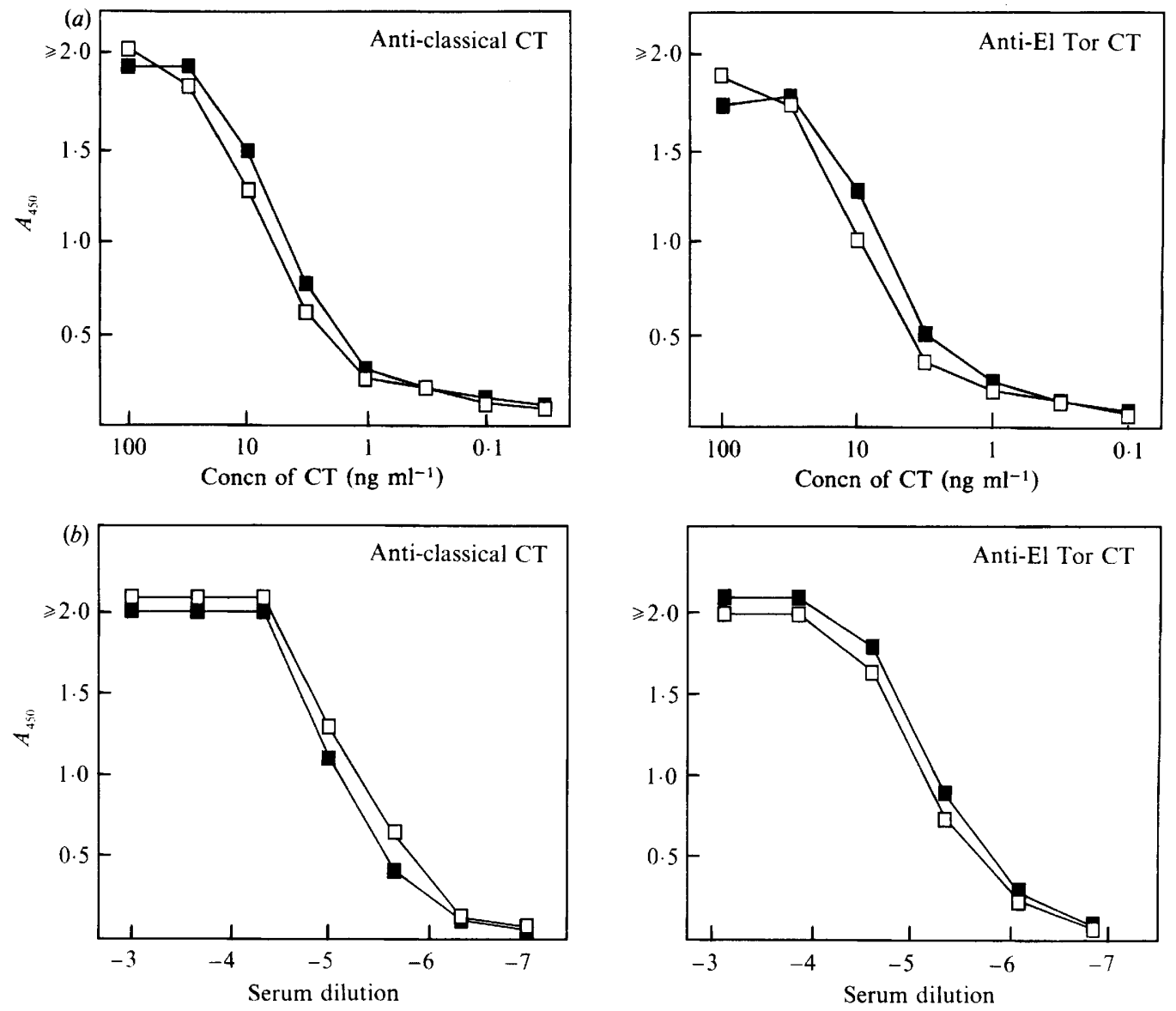

Fig. 5. GM 1 -ELISA comparisons of classical and El Tor CTs. (a) Binding of classical ( $\square$ ) and El Tor ( $\square$ ) CTs in different concentrations to plastic-coated $\mathrm{GM}_{1}$ ganglioside, followed by reaction with an excess concentration of homologous or heterologous polyclonal anti-CT immune serum (diluted $1: 1000$ ). (b) Reactivity of a fixed amount of GM $_{1}$-bound classical ( $\square$ ) and El Tor ( $\square$ ) CTs with serial dilutions of homologous and heterologous polyclonal anti-CT immune sera. $A_{450}$ values were read after 15 min incubation of wells with substrate. 
Table 3. Neutralization tests of El Tor and classical CTs

CTs were prepared from one classical strain (569B) and $10 \mathrm{El}$ Tor strains by growing the organisms under AKI incubation conditions in the presence of antiserum to soluble $\mathrm{HA} /$ protease to protect CTA from being degraded. Bacterial cells were removed by two rounds of high-speed centrifugation followed by sterile filtration, and then the toxic activity in supernatant medium was tested after mixing equal volumes of medium and a $1: 10$ dilution of either rabbit antiserum against classical (R967) CTB, antiserum against El Tor (R1666) CT (in practicality an anti-El Tor CTB preparation) or normal rabbit serum. All the CT samples tested were completely neutralized by both the anti-classical and anti-El Tor sera.

\begin{tabular}{lc}
\hline \hline \multicolumn{1}{c}{ CT } & $\begin{array}{c}\text { Blueing zone diameter (mm) } \\
\text { by rabbit skin test in presence } \\
\text { of normal rabbit serum }\end{array}$ \\
\hline Purified classical CT (569B) & 9 \\
Crude E1 Tor CT preparations & \\
from strain: & \\
VM12718 & 8 \\
VM29017 & 9 \\
T19479 & 6 \\
VM14169 & 7 \\
N16961 & 8 \\
VM19575 & 8 \\
VM45216 & 7 \\
VM12260, VM10289, VM40806 & 0 \\
\hline \hline
\end{tabular}

analyses antiserum reactivity was tested in considerable antibody excess, other $\mathrm{GM}_{1}$-ELISA experiments were done in which a saturating concentration of the two types of CT was attached to the $\mathrm{GM}_{1}$-coated plastic wells and the reactivity then determined with serial dilutions of homologous and heterologous antiserum, respectively. The results, shown in Fig. 5(b), support the previous results that the two types of toxin were indistinguishable in $\mathrm{GM}_{1}$-ELISA despite the immunological difference observed in immunodiffusion analyses.

Neutralization tests. From a practical immunological standpoint the most important consideration is whether antisera raised against El Tor and classical CTs, respectively, can fully neutralize the heterologous as well as the homologous toxin. We therefore performed neutralization tests as described in Table 3 . Seven of the $10 \mathrm{El}$ Tor strains tested produced biologically active toxin giving rise to typical skin 'blueing' reactions when tested in the presence of normal rabbit serum: this CT activity was completely neutralized by either anticlassical or anti-El Tor CTB antiserum. Conversely, a preparation of classical CT (from strain 569B) was also fully neutralized by antisera to $\mathrm{CT}$ irrespective of biotype (Table 3).

\section{Discussion}

Our studies confirm that significant enhancement in CT production by El Tor $V$. cholerae strains is achieved when organisms are cultured using the AKI conditions. None of the 55 tested El Tor strains produced more than $40 \mathrm{n} \mathrm{CT} \mathrm{ml}^{-1}$ in Syncase medium. In contrast, nine of these strains produced more than $1 \mu \mathrm{g} \mathrm{CT} \mathrm{ml}^{-1}$ in AKI medium with $4 \mathrm{~h}$ stationary culture followed by $16 \mathrm{~h}$ shaking culture. In our experiments $\mathrm{CT}$ production increased substantially when the organisms were cultured in larger volumes during the shaking phase: 10-50-fold greater toxin levels were achieved when $500 \mathrm{ml}$ cultures were shaken in 21 flasks compared to $10 \mathrm{ml}$ cultures shaken in $250 \mathrm{ml}$ flasks with similar inoculum size. This may suggest that factors other than excessive aeration may influence CT production during the shaking phase.

In the purification of CT from hypertoxigenic mutants of classical $V$. cholerae and El Tor strains several workers have used sodium hexametaphosphate or aluminium hydroxide precipitation as an initial purification step (Mekalanos et al., 1978; Iwanaga et al., 1986). Among conventional inorganic chemicals used during initial purification steps, aluminium hydroxide at a concentration of $1 \mathrm{mg} \mathrm{ml}^{-1}$ could adsorb toxin almost free from other contaminating proteins. Thus, aluminium hydroxide can be advocated as a more suitable chemical than the other salts tested in the isolation of almost pure CT from El Tor strains in a rapid single-step process. Since the yield of aluminium-hydroxide-adsorbed CT was rather poor, however, we did further purification studies using sodium hexametaphosphate-precipitated CT from culture supernate of strain VM10289 followed by affinity chromatography on a lyso-GM $\mathrm{GM}_{1}$ gangliosideSpherosil column, which resulted in isolation of pure CTB as evidenced by SDS-PAGE.

Characterization of the subunit structure of purified CT from El Tor strains in SDS-PAGE or $\mathrm{GM}_{1}$-ELISA revealed a conspicuous lack of CTA, whilst the pentameric CTB component had similar properties to CTB from classical (569B) V. cholerae. Our results indicate that the explanation for this was a selective degradation of CTA by soluble $\mathrm{HA} /$ protease, which is produced in higher amounts by El Tor as compared with classical $V$. cholerae strains (G. Jonson and others, unpublished). In support of this, when El Tor CT was prepared by affinity isolation from growth medium containing specific antiserum against soluble HA during bacterial growth and toxin production, it revealed the same subunit structure (1A:5B) (Lönnroth \& Holmgren, 1973; Holmgren, 1981) as 569B isolated under the same conditions.

We were especially concerned with the immunological 
properties of El Tor CT and most particularly with the degree of antigenic similarity between El Tor and classical CTB. Our Ouchterlony immunodiffusion-in-gel analyses indicated that both classical and El Tor CTB had major shared epitopes as well as weaker biotypespecific epitopes. By examining such immunological relationships in a two-way fashion using antisera against both classical and El Tor CTB, our findings confirm and extend the recent report of Tamplin et al. (1989). These authors, who tested a panel of mAbs against classical CT, found five shared and one unshared epitope between classical and El Tor CTB as well as some variation in the extent of cross-reactivity between different El Tor CTB preparations with some of the anti-classical mAbs.

The functionally critical immunological question in view of current efforts to develop oral cholera vaccines conferring antitoxic in addition to antibacterial immunity (Holmgren et al., 1989) is to what extent the antitoxic protection evoked by a single CTB preparation (such as that from 569B) will also be effective against the CTs produced by different El Tor cholera vibrios. Specifically, can the greater protective efficacy of a recently tested oral whole-cell CTB vaccine against classical as compared with El Tor cholera (Clemens et al., 1990) be explained on the basis of functionally important CTB epitope differences between CTB classical and El Tor biotypes? Our $\mathrm{GM}_{1}$-ELISA results indicate that classical and El Tor CTB preparations were practically indistinguishable in both $\mathrm{GM}_{1}$ ganglioside and antiserum reactivity. The neutralization tests also demonstrate that antisera raised against $\mathrm{El}$ Tor and classical CT, respectively, can fully neutralize both the homologous and the heterologous CT even though there are some data to suggest that the homologous neutralization under certain conditions might require slightly less antibody (Marchlewicz \& Finkelstein, 1983). Thus, it appears that both toxins, despite their documented epitope differences, are more similar than dissimilar from a practical immunological stand-point. Our data suggest that the unshared, biotype-specific epitopes would not merit priority attention in the further development of oral cholera vaccines.

We thank Professor Ann-Mari Svennerholm for immune reagents and Gunhild Jonson for advice and help with the experiments in Fig. 3. The skilled technical assistance of Christina Olbing is gratefully acknowledged. The work was financially supported by a grant from the Swedish Medical Research Council (project 16x-3383). R.S.D. was supported by a stipend from the Swedish Institute.

\section{References}

BLACK, R. E. (1986). The epidemiology of cholera and enterotoxigenic E. coli diarrhoeal disease. In Development of Vaccines and Drugs against Diarrhoea (11th Nobel Conference, Stockholm 1985), pp. 23-32. Edited by J. Holmgren, A. Lindberg \& R. Möllby. Lund: Studentlitteratur.

Clemens, J. D., SaCk, D. A., Van Loon, F., Chakraborty, J., Ahmed, F., RaO, M. R., HaRris, J. R., Khan, M. R., YunUs, M., Huda, N., Stanton, B. F., Kay, B. A., Walter, S., Eeckels, R., SVenNerholm, A.-M. \& Holmgren, J. (1990). Field trial of oral cholera vaccines in Bangladesh: results from long term follow-up. Lancet i, 270-273.

Craig, J. P. (1965). A permeability factor (toxin) found in cholera stools and culture filtrates and its neutralization by convalescent cholera sera. Nature, London 207, 614-616.

FINKELSTEIN, R. A. (1984). Cholera. In Bacterial Vaccines, pp. 107-136. Edited by R. Germanier. New York: Academic Press.

Finkelstein, R. A. \& Lospalluto, J. J. (1969). Pathogenesis of experimental cholera: preparation and isolation of choleragen and choleragenoid. Journal of Experimental Medicine 130, 185-202.

Finkelstein, R. A., Atthasampunna, P., Chulasamaya, M. \& Charunmethee, P. (1966). Pathogenesis of experimental cholera: biological activities of purified choleragen A. Journal of Immunology 96, 440-449.

HolmGren, J. (1973). Comparison of the tissue receptors for Vibrio chlorae and Escherichia coli enterotoxins by means of gangliosides and natural cholera toxoid. Infection and Immunity 8, 851-859.

HolmGren, J. (1981). Actions of cholera toxin and the prevention and treatment of cholera. Nature, London 292, 413-417.

Holmgren, J., MÅnsson, J. E. \& Svennerholm, L. (1974). Tissue receptor for cholera exotoxin: structural requirements of $\mathbf{G M}_{1}$ ganglioside in toxin binding and inactivation. Medical Biology 52, 229-233.

holmgren, J., Clemens, J., Sack, D. A. \& Svennerholm, A.-M. (1989). New cholera vaccines. Vaccine 7, 94-96.

IwanaGa, M. \& Yamamoto, K. (1985). New medium for the production of cholera toxin by Vibrio cholerae Ol biotype El Tor. Journal of Clinical Microbiology 22, 405-408.

IWANAGA, M. \& KUYYAKANOND, T. (1987). Large production of cholera toxin by Vibrio cholerae $\mathrm{O} 1$ in yeast extract peptone water. Journal of Clinical Microbiology 25, 2314-2316.

Iwanaga, M., Yamamoto, K., Higa, N., IChinose, Y., NaKasone, N. \& TANABE, M. (1986). Culture conditions for stimulating cholera toxin production by Vibrio cholerae $\mathrm{O} 1 \mathrm{El}$ Tor. Microbiology and Immunology 30, 1075-1083.

Kusama, H. \& Craig, J. P. (1970). Production of biologically active substances by two strains of Vibrio cholerae. Infection and Immunity 1 , 80-87.

LAEMmLI, U. K. (1970). Cleavage of structural proteins during the assembly of the head of bacteriophage T4. Nature, London 227, 680-685.

LindHolm, L., Holmgren, J., Wikström, M., KarlsSon, U., ANDERSON, K. \& LYCKe, N. (1983). Monoclonal antibodies to cholera toxin with special reference to cross-reactions with Escherichia coli heat labile enterotoxin. Infection and Immunity 38, 267-272.

LÖNNROTH, I. \& HoLMGREN, J. (1973). Subunit structure of cholera toxin. Journal of General Microbiology 76, 417-427.

MARChlEWICZ, B. A. \& Finkelstein, R. A. (1983). Immunological differences among the cholera/coli family of enterotoxins. Diagnostics in Microbiology and Infectious Diseases 1, 129-138.

Mekalanos, J. J., Collier, R. J. \& Romig, W. R. (1978). Purification of cholera toxin and its subunits: new methods of preparation and the use of hypertoxinogenic mutants. Infection and Immunity 20, 552-558.

Moss, J. \& Vaughan, M. (1977). Mechanism of action of choleragen. Evidence for ADP-ribosyl transferase activity with arginine as an acceptor. Journal of Biological Chemistry 252, 2455-2457.

OUCHTERLONY, Ö. \& NiLSSON, L.-A. (1978). Immunodiffusion and immunoelectrophoresis. In Handbook of Experimental Immunology, pp. 1-44. Edited by D. M. Weir. Oxford: Blackwell.

SVenNerholm, A.-M. \& Holmgren, J. (1986). Oral combined B subunit-whole cell cholera vaccine. In Development of Vaccines and Drugs against Diarrhoea (11th Nobel Conference, Stockholm 1985), pp. 33-43. Edited by J. Holmgren, A. Lindberg \& R. Möllby. Lund: Studentlitteratur. 
SVennerholm, A.-M., Strömberg, G. J. \& Holmgren, J. (1983). Purification of Vibrio cholerae soluble hemagglutinin and development of enzyme-linked immunosorbent assays for antigen and antibody quantitations. Infection and Immunity 41, 237-243.

SVENNERHOLM, A.-M., WiKSTRöM, M., LindBLAD, M. \& HolmGREN, J. (1986). Monoclonal antibodies to Escherichia coli heat-labile enterotoxins: neutralising activity and differentiation of human and porcine LTs and cholera toxin. Medical Biology 64, 23-30.

TAMPlin, M. L., AHMED, M. K., Jalali, R. \& Colwell, R. R. (1989). Variation in epitopes of the B subunit of El Tor and classical biotype
Vibrio cholerae $\mathrm{O} 1$ cholera toxin. Journal of General Microbiology 135 , 1195-1200.

Tayot, J. L., Holmgren, J., Svennerholm, L., Lindblad, M. \& TARDY, M. (1981). Receptor specific large scale purification of cholera toxin on silica beads derivatized with lyso $\mathrm{GM}_{1}$ ganglioside. European Journal of Biochemistry 113, 249-258.

WADSWORTH, C. (1957). A slide microtechnique for the analysis of immune precipitates in gel. International Archives of Allergy and Applied Immunology 10, 335-360. 